\title{
Raman microspectroscopy and Raman imaging of fluid inclusions as method of phase identification.
}

\author{
S. Mamedov \\ Horiba Scientific, Edison, NJ, USA
}

Raman microspectroscopy and Raman imaging are a powerful tool that have been applied widely to characterize a variety of fluid and solid materials. Whereas microspot Raman analyses have been used with great success to identify and characterize materials, it has previously been less useful for characterizing minor components in samples and for characterizing sample heterogeneities.

Minerals often contain fluids or gases in bubbles (fluid inclusions) that have been trapped during crystal formation and thus can provide information about the conditions existing during mineralization - composition, temperature, and pressure. The size of fluid inclusions ranges from less than a micrometer to several hundred micrometers in diameter. Many fluid and gas phases that are common in fluid inclusions, including $\mathrm{H}_{2} \mathrm{O}, \mathrm{CO}_{2}, \mathrm{CH}_{4}, \mathrm{H}_{2} \mathrm{~S}$ etc., are easily recognized by Raman spectroscopy and in some cases quantified using their Raman band intensities and/or positions. Recently, there has been much interest in searching for small amounts of $\mathrm{H}_{2} \mathrm{O}$ in fluid inclusions that previously had been thought to contain only $\mathrm{CO}_{2}$. Confirming the presence of even small amounts of water in fluid inclusions is important in understanding some upper mantle processes in which, as a result of exposure to high temperatures and pressures, hydrated minerals lose water that may then occupy fluid inclusion. At room temperature, the liquid $\mathrm{H}_{2} \mathrm{O}$ phase occurs as a thin, sub-microscopic rim on the walls of the inclusion, it has therefore been difficult, if not impossible, to locate the $\mathrm{H}_{2} \mathrm{O}$ film using spot analysis. Raman imaging, however, facilitates the search for $\mathrm{H}_{2} \mathrm{O}$ in these inclusions and provides a rapid method to survey large number of fluid inclusions to see which, if any contain $\mathrm{H}_{2} \mathrm{O}$. Multivariate analysis methods are used to construct the Raman maps and indicate the presence, in this case, of water and other substances.

Three fluid inclusions in quartz from the Box Vein of Lyonsdale (Port Leyden, NY, USA) have been studied. Spectra from the gas phase are a mixture of $\mathrm{CH}_{4}\left(2911 \mathrm{~cm}^{-1}\right), \mathrm{N}_{2}\left(2325 \mathrm{~cm}^{-1}\right)$, solid carbon phase $\left(1350 \mathrm{~cm}^{-1}\right.$ and $\left.1597 \mathrm{~cm}^{-1}\right)$ and liquid $\mathrm{H}_{2} \mathrm{O}$ phase $\left(3200-3700 \mathrm{~cm}^{-1}\right)$ and shown on the figure 1. Raman bands of carbon dioxide $\left(\mathrm{CO}_{2}\right)$ at $1285 \mathrm{~cm}^{-1}$ and $1388 \mathrm{~cm}^{-1}$ were not found in these inclusions. Raman image of quartz, methane and carbon along with optical image are shown on figure 2. Raman image overlaid on optical image is shown on Figure 2c.It will allow one to identify part of the inclusion which contains methane and carbon. Photo-induced damage on the inner surface of the inclusion was found at high power of laser beam. However, spectral features are the same at high and low power (no damage) and Raman spectrum is very similar to the spectrum of amorphous carbon.

Two other inclusions contain water (Raman peak centered at $3500 \mathrm{~cm}^{-1}$ ) and methane (Raman peak at $2916 \mathrm{~cm}^{-1}$ ) but don't show spectral feature of carbon (Raman peak at $1585 \mathrm{~cm}^{-1}$ ). Depth profile shows distribution of methane in the inclusions and allows one to calculate size of the inclusions. 
The author acknowledges Dr. R.S. Darling (SUNY Cortland, Cortland, NY USA) for samples of fluid inclusions and useful discussions.

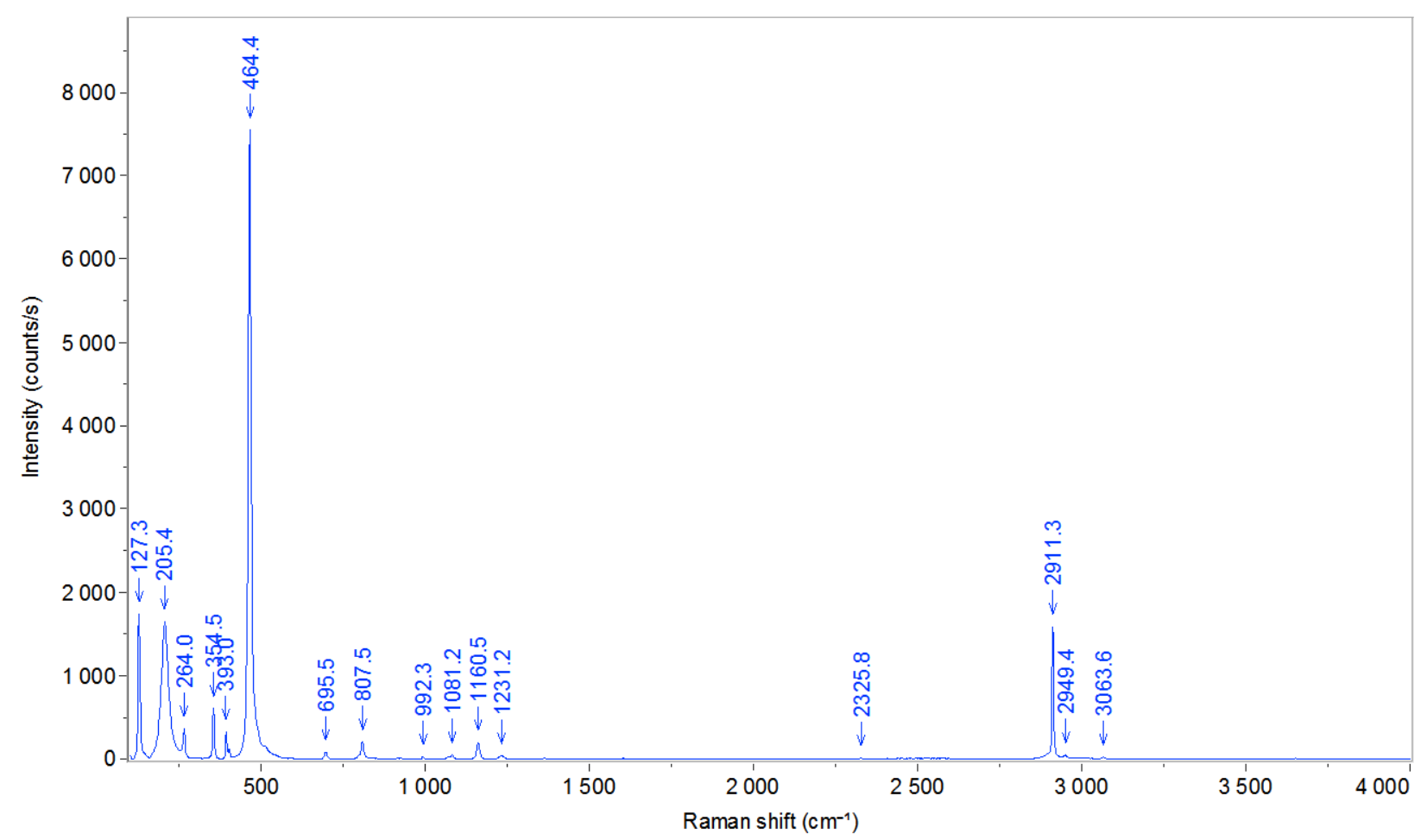

Figure 1. Raman spectrum of inclusion 1. See description in the text.

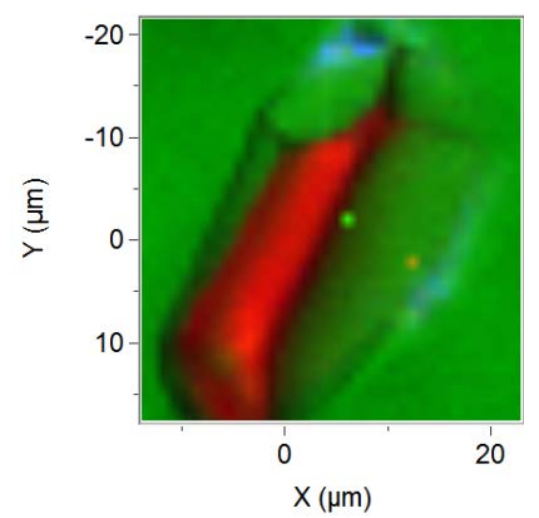

a

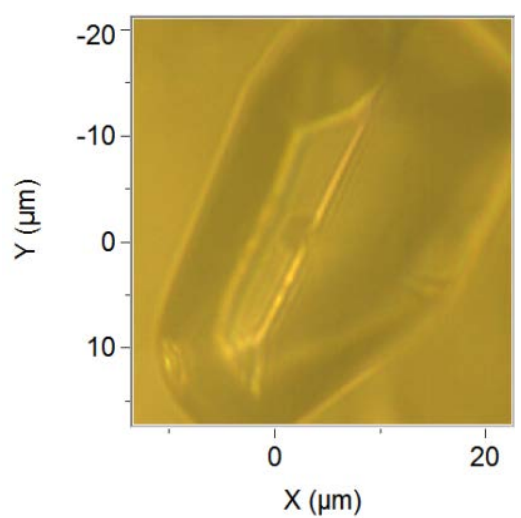

$\mathrm{b}$

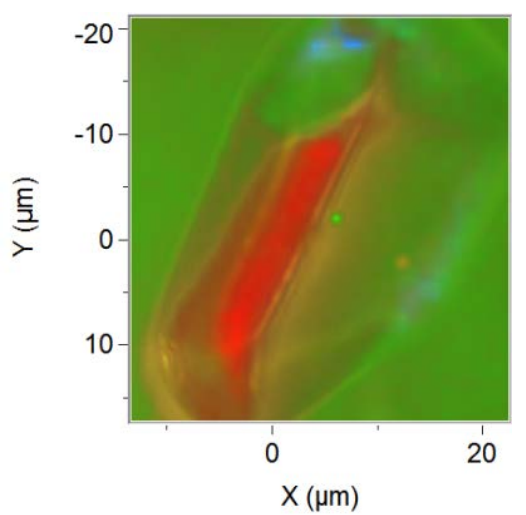

$\mathrm{C}$

Figure 2. a) Raman image of the inclusion 1. Green - $\mathrm{SiO}_{2}$, Red - methane, blue - carbon; b) optical image; c) overlay Raman image and optical image of the inclusion 1. 